\title{
Matching Learning Material to People with Disabilities based on Competence and Functional Capability
}

\author{
Sasithorn Mongkolsripattana \\ School of Electronic and Computer Science \\ University of Southampton \\ Southampton, SO17 1BJ, United Kingdom \\ sm5e14@ecs.soton.ac.uk
}

\author{
Mike Wald and Gary B Wills \\ School of Electronic and Computer Science \\ University of Southampton \\ Southampton, SO17 1BJ, United Kingdom \\ \{mw, gbw $\} @$ ecs.soton.ac.uk
}

\begin{abstract}
Lifelong learning is a very important activity especially for disabled learners. Learning technology allows disabled learners to acquire knowledge and skills more conveniently and effectively. Designing a learning environment should consider accessibility in order to provide an opportunity for those learners to access learning material and information. Much research has focused on improving the discovery of learning materials suitable for the needs of those with disabilities. However, there is no standard approach to adaptive techniques for discovering suitable materials. Most current practice focuses on disability type without considering learners' competence. This research proposes a model that addresses the challenge of accessible learning material based on people's competences and functional capability. This model includes data preparation, matching, and presentation.
\end{abstract}

Keywords - e-learning; learning material; competence; disability; lifelong learning.

\section{INTRODUCTION}

Lifelong learning is important because it is a way of maintaining skills to live independently, to find a job, and to take an active part in society. However, the number of disabled people who take part in lifelong learning or higher education is very low as a result of a lack of accessible learning materials, adapted learning materials and easily understood information [1]. The United Nations (UN) has tried to promote lifelong learning opportunities for all people and to emphasize the inclusive equitable quality of education (Goal 4) in RIO United Nations Conference on Sustainable Development.

It is estimated that $15 \%$ of the world population is disabled presented by World Health Organization (WHO) in World report on disability, 2011. These people face diverse barriers such as encountering difficulties in accessing information and communication technology, and getting equal access to health care, employment and education.

In the case of education, Web-based technology allows learners to get to a large amount of learning content, but the format and design of that content can be inaccessible for disabled learners. Moreover, it is often difficult to express a specific requirement using keywords on search engines when the learner does not know totally about the requirement such as suitable format or competence level of the learner [2]. For these reasons, disabled leaners have to spend time and effort to find appropriate content and material to learn on the Internet. Moreover, human ability usually changes over time. It is necessary to focus on accessibility to provide opportunities for the disabled to fully access a learning environment that supports their learning.

The notion of competence is progressively significant because it contains intended learning outcomes (ILO) in the process of gaining and updating knowledge [3]. ILO contains learned capability which can be used to evaluate a readiness of learner for further learning rather than assessing knowledge level [3, 4]. Each person has different ILO and competences. Therefore, that person should obtain different learning paths and materials. ILO plays a crucial role as a connector between each node of competence and material.

This research applies competence and accessibility approach to investigate a suitable approach and adapt it in order to find a best solution to help instructors and educators to design learning environments that can support disabled learners not only getting access to learning environment, but also receiving materials appropriate for their needs, learning competence, and physical and contextual ability. Literature review will be presented in the next section, following by a proposed model for lifelong learning for disabled and conclusion will be presented in the last section.

\section{LITERATURE REVIEW}

\section{A. Lifelong learning}

Lifelong learning is a learning process occurring throughout human life and includes formal learning, informal learning, and non-formal learning [5]. Lifelong learning plays a crucial role in well-known organisations such as the European Union (EU), the United Nations Educational, Scientific and Cultural Organization (UNESCO), and the Organisation for Economic Cooperation and Development (OECD). However, there are diverse obstacles to undertaking lifelong learning such as 
access barriers, information barriers, and learning design barriers [6]. For the first two, one way to address these barriers is by giving more and better access through distance education. For the last barrier, designing learning processes and materials that are suitable for each individual should be performed to support the learning needs, the learning difficulties, and the background of learners. This research will focus on overcoming these barriers by establishing online learning which provides materials that are appropriate for the needs of individual learners.

\section{B. E-learning transactions}

An E-learning transaction is the smallest unit of analysis in teaching and learning that takes account of the situation in which the teacher and the student have an effort to accomplish the same purpose in a particular context [7]. The essential element is 'purpose', which describes the objective of learning or intended learning outcome. It also includes the use of any teaching assets and learning materials [7].

\section{Competence Model}

Competency refers to an ability to do a specific activity, as defined by M. K. Smith in competence and competencies the encyclopedia of informational education. Competency can be defined as the individual's characteristics consisting of knowledge, skill, or ability that are related to higher performance in a job. A competence approach is applied in organizations and institutions [8]. The benefit of developing competence is to improve individual performance in education [8]. Other advantages of using competence are discussed in Nitchot [9], Sampson [10], and Sitthisak et al. [3].

Standards exist for competency, e.g. IMS Reusable Definition of Competency or Educational Objective (IMSRDCEO) and HR-XML. These standards have limitations where subject matter and capability verbs are unstructured text $[3,9]$, information such as title are not straight machineunderstandable and these standards do not consider a proficiency level which is an important part in competence approach [10]. Sitthisak and Gilbert [3] proposed the competency model called "Competence-Based learner knowledge for personalized Assessment" (COMBA) in order to represent a learner's capability in a multidimensional structured format. The important components of COMBA model comprises of subject matter, capability and context. The Intended learning outcome is the combination of capability with subject matter. Each person may have different competency levels in a particular intended learning outcome based on the context [9].

\section{Disability and Accessibility}

The definitions of disability have been developed and used in different disciplines and contexts as well as for different purposes [11]. Disabilities can be grouped according to the type of impairment: visual impairment, hearing impairment, mobility impairment, and cognitive impairment [12]. Different types of impairment can perceive different content formats based on their abilities. Understanding these needs will help developers provide suitable content format to disabled people.

Accessibility exhibits diverse aspects. On the one hand, accessibility is the designing or developing of products, buildings, services or environments for disabled people. On the other hand, accessibility refers to "the ability to access" information, internet or the web for people with disabilities described by WAI. According to United Nation, Convention on the rights of persons with disabilities, providing accessibility for disabled people encourages equality not only in accessing information, the web or the internet, but also in the use of products, services or environments on an equal basis with other people.

Although there are specifications and guidelines for designing and developing web pages, such as Universal design, Web Content Accessibility Guideline (WCAG2.0) [13], The IMS ACCMD: AccessForAll Meta-data, and the IMS AccLIP: Accessibility for Learner Information Package, they do not provide specific detail to match content and learners' abilities. These guidelines mainly focus on groups of disability rather than level of abilities or impairments of each individual. An assistive technology plays an important role in accessing web content for disabled people, but each person has an individual requirement to use different kinds of assistive technology and in some situations there are limits on the use of such technologies [14]. Providing appropriate content format based on people abilities should be considered.

This research will take accessibility into account in order to provide an opportunity for disabled people to be able to access learning material based on their competences and abilities.

\section{E. Material/resource/content}

Learning materials are "anything used for teaching and learning". Online material uses metadata to describe characteristics of the material. Metadata is structured information for describing, explaining, locating or retrieving an information resource. Common metadata for describing material/content include title, language, description, and type of material. Moreover, each material item should have a description that explains the objective of the material or learning objectives which the material is used to support.

Different metadata schemas have developed in diverse environments. The common metadata standards and specifics for resource or material in e-learning consist of the Dubbin Core Metadata, IEEE LOM (IEEE Learning Object Metadata), and SCORM (Sharable Content Object Reference Model). These standards enable learning resource to be interoperable and reusable between various learning resource systems [15]. The IEEE LOM contains attributes describing pedagogical view of learning resources. However, this standard does not directly support description of learning resource in terms of competence and accessibility [15]. Another important metadata schema 
which major search engines such as Google, Bing, and Yahoo use is the schema from "Schema.org".

\section{RESEARCH ON PROVIDING MATERIAL TO LEARNERS}

Learners who paticipate in lifelong learning not only have various backgrounds and different trait, but they might also change learning objective/goal, context, and enviroment. Therefore, an effective learning environment should have the ability to recognize learner's learning situation and provide personalisation and adapt learning environment.

Personalised learning was developed within the field of intelligent tutoring systems (ITS) and adaptive Hypermedia (AH) systems [16]. AH and ITS systems employ a user model to adapt their navigation or content according to the individual user $[9,17]$. Popular factors for creating a user model are: user's knowledge, interests, goals, background, and context of work [17]. However, ITS and AH have limitations discussed by Nitchot [9] and Yarandi et al. [16] such as restricting the opportunities to support free exploration [16] or requiring update material when knowledge changes, causing high additional development cost [9]. In addition, modelling the user based on their profile may be incorrect because the user model draws mostly upon presumption about users [18]. Importantly, there are no standard approaches to adaptive techniques in the system [9, $18]$.

Sitthisak and Gilbert [3] explored the problems of adaptive assessment systems and suggested to use "learned capability" rather than assessing knowledge level in order to solve those problems. The capability can be assessed from competencies achieved in each course [3]. Much research discusses the benefits of considering competence and of taking competence into account, such as Nitchot [9], Sampson [10], Magdaleno-palencia et al. [11], Sampson \& Zervas [15], and Shen and Shen [19].

TABLE I SUMMARY OF RESEARCH BY RELATED FIELD OF DISABILITY, CONTENT, AND COMPETENCE

\begin{tabular}{|c|c|c|c|c|c|c|c|c|}
\hline & \multirow[b]{2}{*}{ Author } & \multicolumn{3}{|c|}{ Disability } & \multirow[b]{2}{*}{ 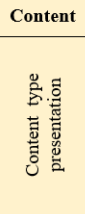 } & \multicolumn{3}{|c|}{ Competence } \\
\hline & & 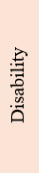 & 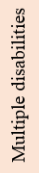 & 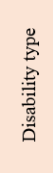 & & 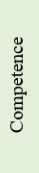 & 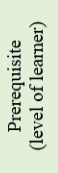 & 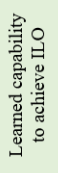 \\
\hline 1 & Douce et al. , 2010 [22] & $\sqrt{ }$ & & A & $\sqrt{ }$ & & & \\
\hline 2 & Laabidi et al., 2014 [21] & $\sqrt{ }$ & $\sqrt{ }$ & A & $\sqrt{ }$ & & & \\
\hline 3 & Lancheros et al., $2011[20]$ & $\sqrt{ }$ & & $\mathrm{H}$ & $\sqrt{ }$ & & & \\
\hline 4 & Magdaleno-palencia et al., 2011 [11] & & & & & $\sqrt{ }$ & & $\sqrt{ }$ \\
\hline 5 & Nganji and Brayshaw, 2015 [23] & V & $\sqrt{ }$ & A & $\sqrt{ }$ & & & \\
\hline 6 & Nitchot, $2012[9]$ & & & & & $\sqrt{ }$ & $\mathrm{V}$ & $\sqrt{ }$ \\
\hline 7 & Sampson, $2009[10]$ & $\sqrt{ }$ & & $\mathrm{M}, \mathrm{V}$ & $\sqrt{ }$ & & & \\
\hline 8 & Sampson and Zervas, 2011 [15] & $\sqrt{ }$ & $\sqrt{ }$ & A & $\sqrt{ }$ & & & \\
\hline 9 & Shen and Shen, 2004 [19] & & & & & $\sqrt{ }$ & $\sqrt{ }$ & \\
\hline
\end{tabular}

\section{A. Providing material for disabled people}

There are some research providing personalised learning material to meet disabled learners' requirements. Lancheros et al. [20] provided adaptive display information and personalised content for the hearing impaired. Sampson and Zervas [15] proposed a tool and service to develop an accessibility e-training resource for those with motor disability and low vision by extending the IEEE LOM standard to handle the accessibility and competence characteristics presented by Sampson and Zervas [15]. However, the content so designed is specific only to the accessibility requirements of a particular user group [21]. EU4ALL [22] emphasised functional disabilities in terms of content, display, and control. However, EU4ALL might not support people with multiple disabilities. ONTODAPS (Ontology-driven Disability-aware E-learning System) [23] employs the benefit of an ontology to provide personalised learning resource for learners with multiple disabilities. Most of this research, summarized in Table I, has focused on content presentation/format, and other factors such as learning goal and learning style, without considering learner knowledge or competence level and without considering the integration of external resource like the World Wide Web.

\section{A PROPOSED MODEL FOR LIFELONG LEARNING FOR THE DISABLED}

The aim of this research is to investigate a way to address the challenge of accessible learning materials which can support disabled learners, based on the learner's ability and competence in order to provide an appropriate learning path and learning material from the WWW to support lifelong learning. The three main layers are: data preparation, matching model and presentation layer shown in table. 1.

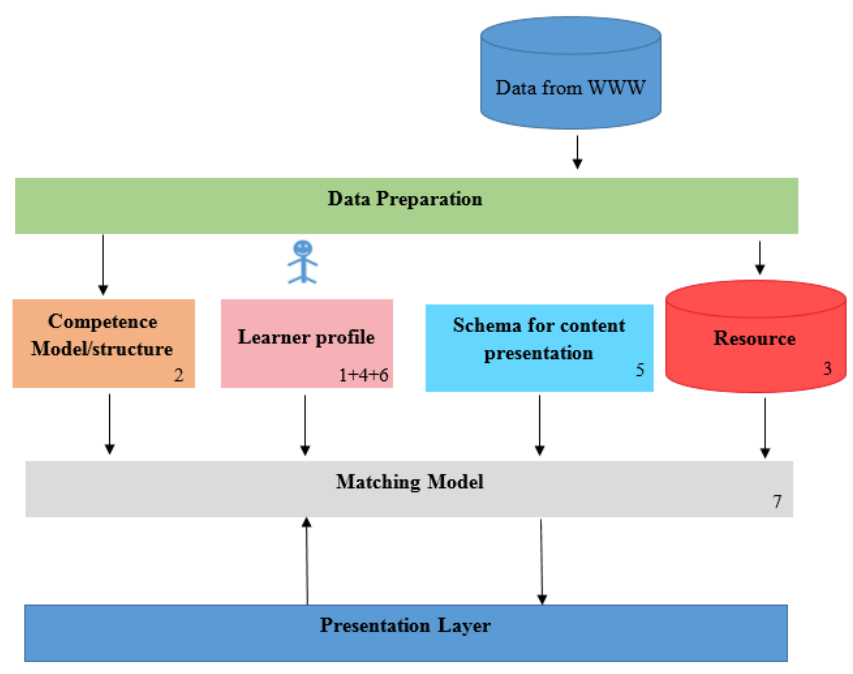

Figure 1. Proposed model

\section{A. Data Preparation}

The data preparation component arises from the challenge of diverse and heterogeneous educational resources available from the WWW, such as Open Educational Resource, DBpedia, and KhanAcademy. This requires the investigation and specification of a method of discovery, access, and pre-processing information from those resources. As learning resources on the WWW are produced by different organisations using different standards, these resources have different schemas, vocabularies and 
interfaces. For this reason, mapping between different kinds of resource description metadata is required by this component before transferring those resources into a generic standard in order to use a universal query. Moreover, in this process the competency structure is created from a syllabus on the WWW or from an expert.

\section{B. Matching model}

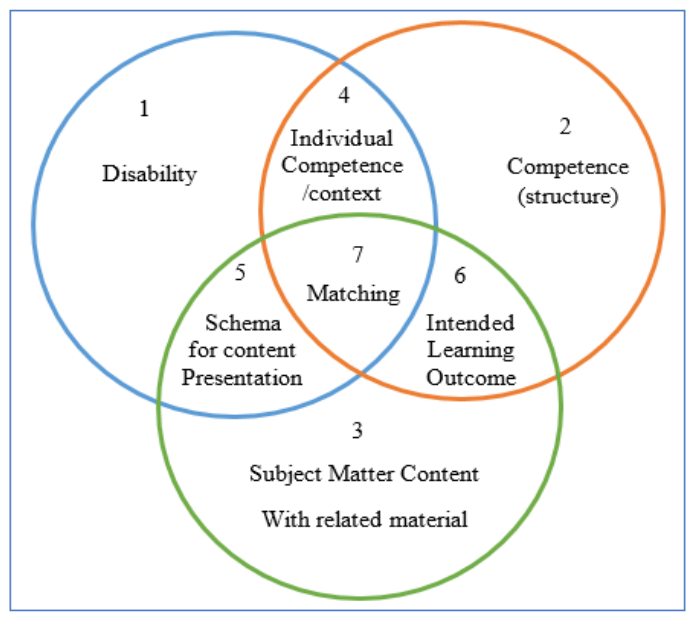

Figure 2. Matching model

As ability varies from person to person, even the human ability to perceive and understand content may be different. Identifying functional abilities of the person helps designers and developers to suggest appropriate content according to a person's ability. Table II shows the matching between content types, content formats and functional abilities. Contents can be mainly grouped: image, video, audio, and textual. Likewise, content formats can be categorized into:
The matching model, shown in Fig. 2, consists of three main areas: disability, competence, and subject matter content. Three area of overlap are intended learning outcome (ILO), schema for content presentation, and individual competence and context. ILO, the objective of overall teaching and learning of e-learning transaction [7], is applied in order to map the relationship between competence and subject matter content. The objective of the competency model, such as COMBA [3], is to develop competence in the cognitive domain by mainly focusing on capability related to subject matter content. Able people can also gain a benefit from the competency model. However, disabled people, who have some perception limitation or impairment such as visual or hearing, might not be able to perform to some level of competence.

For example, visually impaired people face difficulties in achieving drawing competence because the context that they undertake is not suitable for them. Context may be content type or assistive technology. Therefore, the learner profile should be studied in order to investigate what capabilities and context matches with the perception of each person. Accessibility guidelines for designing and developing accessibility content [13] are used for creating schema to find appropriate content presentation for people with diverse abilities.

Feature is used to describe the characteristic that content should have to enable people who cannot perceive some types of content to understand that content. For example, a person with profound hearing cannot hear an audio content, but he or she can understand this audio when it is captioned or has text transcription. Feature might be used for searching content that is suitable for individual abilities.

TABLE II. METHOD FOR MATCHING FUNCTIONAL CAPABILITY WITH CONTENT TYPE AND CONTENT FEATURE

\begin{tabular}{|c|c|c|c|c|c|c|c|c|c|c|c|c|c|c|c|c|c|}
\hline \multirow{3}{*}{ Type } & \multirow{3}{*}{ Feature } & \multirow[b]{3}{*}{$\begin{array}{l}\text { Reference of } \\
\text { feature }\end{array}$} & \multirow[b]{3}{*}{$\begin{array}{c}\text { Access } \\
\text { Mode } \\
{[24]}\end{array}$} & \multirow{2}{*}{\multicolumn{4}{|c|}{ Content format $[24,20]$}} & \multicolumn{10}{|c|}{ Functional abilities/disabilities } \\
\hline & & & & & & & & \multicolumn{4}{|c|}{ Hearing / auditory [9] } & & \multicolumn{3}{|c|}{ Vision/visual [9] } & \multirow{2}{*}{ Cognition } & \multirow{2}{*}{$\begin{array}{c}\text { Mobilit } \\
\mathbf{y}\end{array}$} \\
\hline & & & & Auditory & Tactile & Textual & Visual & Mild & Moderate & Severe & Profound & $\begin{array}{l}\text { Deaf- } \\
\text { blind }\end{array}$ & Blindhess & Low vision & $\begin{array}{l}\text { Colour } \\
\text { blind }\end{array}$ & & \\
\hline \multirow[t]{3}{*}{ Image } & & {$[24,25,13]$} & Visual & & & & $\mathrm{v}$ & $\mathrm{v}$ & $\mathrm{v}$ & $\mathrm{v}$ & $\mathrm{v}$ & $\times$ & $x[4]$ & $\mathrm{v}$ & $v[13]$ & 。 & $\mathrm{v}$ \\
\hline & alternative text & {$[24,13]$} & & & & $\mathrm{v}$ & & $\mathrm{v}$ & $\mathrm{v}$ & $\mathrm{v}$ & $v$ & $\times$ & $v[4]$ & $\mathrm{v}$ & $\mathrm{v}$ & $\mathrm{v}$ & $\mathrm{v}$ \\
\hline & audio description & {$[25,28]$} & & $\mathrm{v}$ & & & & $\mathrm{v}$ & $\mathrm{v}$ & $x$ & $x$ & $x$ & $\mathrm{~V}[25,28]$ & $\mathrm{v}$ & $\mathrm{v}$ & $\mathrm{v}$ & $\mathrm{v}$ \\
\hline \multirow[t]{5}{*}{ Video } & & {$[24,4,13]$} & Visual/music & $\mathrm{v}$ & & $\mathrm{v}$ & $\mathrm{v}$ & $\mathrm{v}$ & $\mathrm{v}$ & $x$ & $x$ & $x$ & $\times$ & $\mathrm{v}$ & $\mathrm{v}[13]$ & $\mathrm{v}[13]$ & $\mathrm{v}$ \\
\hline & text transcript & {$[25,14,13]$} & & & & $\mathrm{v}$ & & $v[14]$ & $v[14]$ & $v[14]$ & $v[14]$ & $\times$ & $\times$ & 。 & $\mathrm{v}$ & $\mathrm{v}$ & $\mathrm{v}$ \\
\hline & caption & {$[24,26,14]$} & & & & $\mathrm{v}$ & & $v[14,27]$ & $v[14,27]$ & $v[14,27]$ & $v[14,27]$ & $\times$ & $x$ & $\circ$ & $\mathrm{v}$ & $\mathrm{v}$ & $\mathrm{v}$ \\
\hline & audio transcript/description & {$[25,26,14,13]$} & & $v[28]$ & & & & $v$ & $v$ & $\times$ & $\times$ & $\times$ & $v[27,4,14,28]$ & $v[27,14,28]$ & $v[27,14]$ & $v[27,14]$ & $\mathrm{v}$ \\
\hline & sign language & {$[14]$} & & & & & $v[28]$ & $\times$ & $x$ & $v[14]$ & $v[14]$ & $x$ & $\times$ & $\times$ & $\times$ & $\times$ & $\times$ \\
\hline \multirow[t]{4}{*}{ Audio } & & {$[24,25,13]$} & Auditory & $\mathrm{v}$ & & & & $\mathrm{v}$ & $\mathrm{v}$ & $\times$ & $\times$ & $x$ & $\mathrm{v}[23]$ & $v[23]$ & $\mathrm{v}$ & $v[23]$ & $\mathrm{v}$ \\
\hline & text transcript/description & {$[24,13]$} & & & & $\mathrm{v}$ & & $v$ & $v$ & $\mathrm{v}$ & $v$ & $x$ & $\times$ & $\mathrm{v}$ & $\mathrm{v}$ & $\mathrm{v}$ & $\mathrm{v}$ \\
\hline & caption & [26] & & & & $\mathrm{v}$ & & $\mathrm{v}$ & $\mathrm{v}$ & $v$ & $v$ & $\times$ & $x$ & 。 & 。 & $\times$ & $\mathrm{v}$ \\
\hline & sign language & [26] & & & & & $\mathrm{v}$ & $\times$ & $\times$ & $\mathrm{v}$ & $\mathrm{v}$ & $\times$ & $\times$ & $\times$ & $\times$ & $\times$ & $\times$ \\
\hline \multirow[t]{4}{*}{ Textual } & & {$[24,25]$} & Textual & & & $\mathrm{v}$ & & $v[23]$ & $v[23]$ & $v[23]$ & $v[23]$ & $\times$ & $x[4]$ & $\circ$ & 。 & $x[4]$ & $v[23]$ \\
\hline & speech output & {$[28]$} & & $\mathrm{v}$ & & & & $\mathrm{v}$ & $\mathrm{v}$ & $\times$ & $\times$ & $x$ & $v[28]$ & $\mathrm{v}$ & $\mathrm{v}$ & $v[4]$ & $\mathrm{v}$ \\
\hline & adjust font type/size & {$[25,28]$} & & & & $\mathrm{v}$ & & $\mathrm{v}$ & $\mathrm{v}$ & $\mathrm{v}$ & $\mathrm{v}[28]$ & $x$ & $\times$ & $v[26,28]$ & $v[26,28]$ & $v[26]$ & $\circ$ \\
\hline & adjust text background colour & {$[25]$} & & & & $\mathrm{v}$ & & $\mathrm{v}$ & $\mathrm{v}$ & $\mathrm{v}$ & $\mathrm{v}$ & $\times$ & $\times$ & $\mathrm{V}[26,28]$ & $\mathrm{v}[26]$ & $v[26,28]$ & $\circ$ \\
\hline Braille & & {$[24]$} & Tactile & & $v$ & & & $x$ & $x$ & $x$ & $x$ & $\mathrm{v}$ & $V[4,23]$ & $\times$ & $x$ & $\times$ & $x$ \\
\hline
\end{tabular}

auditory (e.g. speech, music, sound), tactile (e.g. dots and bars), visual (e.g. image, text, and video) [14], and textual. The abilities of users include sensory/perceptual (auditory and vision), cognitive, and mobility [29].
In the analysis, $\sqrt{ }$ indicates a person who has ability in specific column can perceive content in a specific row. The $x$ indicates a person cannot receive content in a specific row. Where an o symbol occurs, it is not clear about a person's perception of each kind of content. 
Area 1: Disability means a learner who has learning difficulty because he/she faces a problem in terms of vision or hearing.

Area 2: Competence structure means the relationship of competence within the structure which can be presented in various ways such as tree, graph, or network [9]. Competence structure could be designed from the available learning outcome from course syllabus, website, or textbook [3].

Area 3: Meaning is a keyword of subject matter content related to study material from the web. Each material should have metadata that describes charateristics of the material such as title, keyword, media format, or description about objective of the material.

Area 4: The intersection area between disability and competence could be described in three questions. (1) what competence supports the individual disabled learner, (2) what competence does the disabled learner finish with, and (3) what is the target competence of the disabled learner. This area relates to the individual competence of each learner. Each disabled learner faces difficulties in performing or achieving different competences. For example, a learner who is blind cannot perform competence related to the ability to pilot an airplane because they connot see. Therefore, selecting the learning path should focus on other paths which these learner can perform, based on individual competence. A disabled learner can perceive each competence according to the context that he/she undertakes. Context is consided as tool, situation, or difficulty that the disabled learner has.

Area 5: The intersection area between disability and subject matter content could be described as the formats of content which a disabled learner can perceive. This research will investigate schema for content presentation that are appropriate to each group of disabled learners shown in table II.

Area 6: The intersection area between competence and material could be described as materials that support each competence. Intended learning outcome is used as a connector between material and competence because intended learning outcome consists of subject matter content that relates to material.

Area 7: Matching means matching for a suggested personal learning path, learning material in appropriate form of presentation to disabled learners based on their competence.

\section{Presentation layer}

The presentation layer is an interface for connecting with learners. Learning path and learning material will be presented to learners based on learner's competence and functional capability.

\section{CONCLUSION}

Previous studies have focused on providing accessibility for disabled people so that they may obtain material based on their profiles such as knowledge level, disability type, and learning goal. However, none of them focuses on functional ability (disability) and competence.

The model proposed has three components: data preparation, matching model, and presentation layer. The data preparation is to prepare data from diverse resources from the WWW and transfer those data in generic format for use in the matching model. The matching model tries to match learner's competence and disability with a matching schema in order to find suitable content presentation for the individual learner. Suitable accessible content presentation and information from the competency model are used as a criteria for recommending learning material from the WWW.

\section{REFERENCES}

[1] L. B. Claiborne, S. Cornforth, A. Gibson, and A. Smith, "Supporting students with impairments in higher education: social inclusion or cold comfort?", International Journal of Inclusive Education, pp.513527, 2011.

[2] K. Verbert, N. Manouselis, X. Ochoa, M. Wolpers, H. Drachsler, I. Bosnic, and E. Duval, E, "Context-aware recommender systems for learning: A survey and future challenges", IEEE Transactions on Learning Technologies, vol. 5(4), pp.318-335, 2012.

[3] O. Sitthisak and L. Gilbert, Competence Modelling and TechnologyEnhanced Learning. Deutschland,Germany: Scholars' Press., 2014.

[4] Falmagne, J., and Cosyn, E. (2006). The Assessment of Knowledge , in Theory and in Practice. In Formal concept analysis ICFCA 2006 (Lecture notes in computer science vol. 3874) (pp. 61-79).

[5] J. DELORS, I. A. Mufti, I. Amagi, R. Carneiro, and F. Chung, Learning: The Treasure within - Report to UNESCO of the International Commission on Education for the Twenty-first Century (Highlights). Paris: UNESCO Publishing, 1996.

[6] N. Longworth, Lifelong learning in action: transforming education in the 21st century. Lifelong Learning (p. 192). London: Kogan Page Limited, 2003.

[7] L. Gilbert, and V. Gale, Principles of E-learning Systems Engineering. Oxford, England: Chados Publishing, 2008.

[8] T. Hoffmann, "The meanings of competency", Journal of European Industrial Training, vol.23, pp.275-286, 1999.

[9] A. Nitchot, A competence-based system for recommending study materials from the Web. University of Southampton, 2012.

[10] D. G. Sampson, "Competence-related Metadata for Educational Resources that Support Lifelong Competence Development Programmes Theoretical background: Competence Definitions and Models for Describing Competences", Educational Technology and Society, 12(August), pp. 149-159, 2009.

[11] J. S. Magdaleno-palencia, M. Garcia-valdez, M. Castanon-puga, and B. Y. Marquez, "Agents Based Adaptive Hypermedia System with the Competency Approach", International Journal on New Computer Architectures and Their Applications (IJNCAA), vol. 1, pp. 1110 $1117,2011$.

[12] A. Kavcic, "Software Accessibility: Recommendations and Guidelines", EUROCON 2005 - The International Conference on Computer as a Tool, vol. 2, pp. 1024-1027, 2005.

[13] B. Caldwell, M. Cooper, L. G. Reid, and G. Vanderheiden, "Web Content Accessibility Guidelines (WCAG) 2.0", 2008. Retrieved February 2, 2015, from http://www.w3.org/TR/WCAG20/

[14] S. Abou-Zahra, "WAI: Strategies, guidelines, resources to make the Web accessible to people with disabilities", 2012. Retrieved July 01, 2015, from http://www.w3.org/WAI/intro/people-use-web/diversity.

[15] D. G. Sampson and P. Zervas, "Supporting accessible technologyenhanced training: The eaccess2learn framework", IEEE Transactions on Learning Technologies, vol 4(4), pp. 353-364, 2011. 
[16] M. Yarandi, H. Jahankhani, A. H. Tawil, "A personalized adaptive e-learning approach based on semantic web technology". In Webology, vol. 10, pp. 1-14, 2013.

[17] P. Brusilovsky, and E. Millán, "User Models for Adaptive Hypermedia and Adaptive Educational Systems", In The Adaptive Web, pp. 3-53, 2007.

[18] A. Kobsa, "User Modeling : Recent Work , Prospects and Hazards", In Adaptive User Interfaces: Principles and Practice, pp. 111-128, 1993.

[19] L. Shen, and R. Shen, (2004), "Learning Content Recommendation Service Based-on Simple Sequencing Specification", In Advances in Web-Based Learning - ICWL 2004, pp. 293-323, 2004.

[20] D. J. Lancheros, A. Carrillo-Ramos, and J. L. Lara, "ALSHI: Adaptive learning system for hearing impaired", In 2011 6th Colombian Computing Congress, CCC 2011, pp. 1-5, 2011.

[21] M. Laabidi, M. Jemni, L. J. Ayed, H. Brahim, and A. Ben Jemaa, "Learning technologies for people with disabilities", Journal of King Saud University - Computer and Information Sciences, vol 26, pp 2945, 2014.

[22] C. Douce, W. Porch, and M. Cooper, "Adapting e-learning and learning services for people with disabilities", In 1st International AEGIS Conference: Access for All in the Desktop, Web and Mobile Field: an End-User and Developer Perspective. Seville, Spain, 2010.
[23] J. T. Nganji, M. Brayshaw, and B. Tompsett, "Ontology-driven disability-aware e-learning personalisation with ONTODAPS", Campus-Wide Information Systems, vol. 30, pp. 17-34, 2013

[24] Schema.org. Retrieved July 01, 2015, from http://schema.org.

[25] IMS Global Learning Consortuim. Retrieved September 20, 2015, from http://www.imsglobal.org/accessibility/accessiblevers/sec5.html.

[26] Web Accessibility in Mind (WebAIM). Retrieved October 25, 2015, from http://webaim.org/articles/.

[27] National Center for Accessibility Media (NCAM). Retrieved September 25, 2015, from http://ncam.wgbh.org/invent_build/web_multimedia/accessibledigital-media-guide.

[28] L. Pyfers, H. Petrie, W. Fisher, G. Weber, K. Gladstone, and C. Rundle, "Universal Interfaces to Multimedia Documents", In Proceedings of the Fourth IEEE International Conference on Multimodal Interfaces, Pittsburgh, PA: IEEE Computer Society Press., vol. 44, pp. 319-324, 2002.

[29] D. Sloan, B elly, A. Heath, H. Petrie, H. Fraser, and L. Phipps, "Contextual Web Accessibility - Maximizing the Benefit of Accessibility Guidelines", In W4A, pp. 121-131, 2006. 